\title{
Overexpressed CD39 mitigates sepsis-induced kidney epithelial cell injury via suppressing the activation of NLR family pyrin domain containing 3
}

\author{
MEIXIA YANG, LINXIN LU, ZHIQIN KANG, TIANLONG MA and YU WANG \\ Department of Emergency, Shanxi Dayi Hospital, Taiyuan, Shanxi 030032, P.R. China
}

Received January 29, 2019; Accepted August 5, 2019

DOI: $10.3892 / \mathrm{ijmm} .2019 .4349$

\begin{abstract}
Unfettered inflammation is a leading cause of multiple organ failures in sepsis. The anti-inflammatory role of cluster of differentiation (CD)39 has been previously reported. The present study aimed to investigate the role of unfettered inflammation in sepsis-induced acute kidney injury (AKI). Lipopolysaccharide (LPS) was introduced to construct a sepsis mouse model. Kidney function and pathological changes in mice were measured at 12, 24 and $48 \mathrm{~h}$. CD39 overexpression and inhibition vectors were transfected into renal tubular epithelial (HK-2) cells, followed by LPS treatment $(10 \mu \mathrm{g} / \mathrm{ml})$, and the cell viability changes at $24 \mathrm{~h}$ after treatment were assessed and the expression of NLR family pyrin domain containing 3 (NLRP3), cleaved caspase-1 and CD39 were determined by performing ELISAs. Cell apoptosis and reactive oxygen species (ROS) levels were determined by flow cytometry. It was found that after LPS administration, kidney injury was the most serious at $24 \mathrm{~h}$ in mice. CD39 overexpression could suppress the upregulation of pro-inflammatory cytokines induced by LPS treatment. In addition, the cell apoptosis and ROS level exhibited an obvious decrease, while cell viability increased. The NLRP3 expression and activity also showed a great inhibition in CD39-overexpressed cells. By contrast to CD39 overexpression, CD39 inhibition promoted the activation of the NLRP3 inflammasome. These data indicate the protective role of CD39 in LPS-induced renal tubular epithelial cell damage through inhibiting NLRP3 inflammasome activation and that CD39 might be a potential therapeutic target in sepsis-induced AKI.
\end{abstract}

Correspondence to: Dr Linxin Lu, Department of Emergency, Shanxi Dayi Hospital, 99 Longcheng Avenue, Xiaodian, Taiyuan, Shanxi 030032, P.R. China

E-mail: linxin_lull@163.com

Key words: pro-inflammatory cytokines, lipopolysaccharide, serum creatinine, hematoxylin and eosin staining

\section{Introduction}

Sepsis, also known as systemic inflammatory response syndrome, arises as a result of an overwhelming immune response to infection, which is highly associated with tissue injury, multiple organ failure and even death $(1,2)$. In addition, sepsis is the most common cause of acute kidney injury (AKI) (3), which is a type of clinical syndrome characterized by a rapid decline in the glomerular filtration rate, resulting in retention of nitrogenous wastes, primary creatinine and blood urea nitrogen (4). The incidence of AKI increases with the severity of sepsis and AKI occurs in $\sim 19 \%$ of patients with moderate sepsis, $23 \%$ with severe sepsis and $51 \%$ with septic shock $(5,6)$. Notably, the mortality rate for AKI patients in the setting of sepsis is approximately twice as high as that for sepsis alone (7). A previous study showed that pathogenesis of sepsis-induced AKI was distinct from AKI without sepsis and some studies demonstrated that sepsis-induced renal ischemia and acute tubular necrosis (ATN) were the primary pathophysiologies to AKI $(8,9)$. However, previous research involving postmortem observations in septic animals and humans showed that sepsis-induced AKI was characterized by obviously bland histology with focal areas of tubular damage, but rare diffuse renal tubular cell death, indicating that ATN could not completely explain this phenotype $(10,11)$. Meanwhile, three distinct alterations [cellular bioenergetic responses to injury (10), diffused microcirculatory flow abnormalities $(12)$ and inflammation $(13,14)]$ were consistently observed regardless of species, organ, disease stage or severity, indicating that these three alterations played vital roles in the progression and development of tubular injury and AKI. This study focused on the mechanism of the inflammatory response in the sepsis-associated AKI and aimed to improve the present status of treatment for AKI.

CD39, alternatively known as ecto-nucleotide triphosphate diphosphohydrolase-1, works as an inflammatory suppressor that could catalyze the conversion of extracellular adenosine triphosphate and diphosphate (ATP and ADP) into adenosine monophosphate and promote the generation of adenosine (15). It is known that the extracellular ATP triggers NLR family pyrin domain containing 3 (NLRP3) inflammasome activation, which could lead to the generation of a series of inflammatory cytokines, such as cleaved caspase-1, interleukin (IL)-1 $\beta$, IL-18, IL-6 and tumor necrosis factor- $\alpha$ (TNF- $\alpha)(16,17)$. Meanwhile, 
adenosine was reported to be anti-inflammatory, immunosuppressive and have protective effects in sepsis-associated organ injury $(18,19)$. Therefore, CD39 plays a suppressive role in the NLRP3 inflammasome activation and its mediated downstream pro-inflammatory cytokines. A study on sepsis-induced liver injury showed that CD39 limited sepsis-caused systemic inflammation and restored liver homeostasis by suppressing the activation of NLRP3 through scavenging eATP and generating adenosine (20). However, the functional effects of CD39 in sepsis-induced AKI are less studied, therefore the present study aimed to investigate whether CD39 effectively exerted its anti-inflammatory activity in sepsis-associated AKI.

\section{Materials and methods}

Animal model of AKI. Adult male C57BL/6 mice $(\mathrm{n}=40$, 6-8 weeks old, 22-26 g) were obtained from the Shanxi Dayi Hospital (Taiyuan, China). All mice were allowed to have free access to food and water and maintained in a specific pathogen-free animal facility under a 12-h light/dark cycle at a controlled temperature $\left(20-24^{\circ} \mathrm{C}\right)$ and in a humid $(50 \pm 5 \%)$ environment. Mice were randomly divided into 4 groups. In the control group, a total of 8 mice were intraperitoneally injected with normal saline (Control). In the lipopolysaccharide (LPS) group, a total of 32 mice were injected with a single dose of LPS (20 mg/kg; Sigma-Aldrich; Merck KGaA). Mice in the LPS and Control group were intraperitoneally anesthetized with $50 \mathrm{mg} / \mathrm{kg}$ of $5 \%$ barbitone and subjected to a thoracic incision 12, 24 and $48 \mathrm{~h}$ after the injection. The blood samples ( $\sim 0.3 \mathrm{ml}$ per mouse) were collected by heart puncture and maintained at $37^{\circ} \mathrm{C}$ for $30 \mathrm{~min}$. After $10 \mathrm{~min}$ of centrifugation at $3,500 \mathrm{x} \mathrm{g}$ at $4^{\circ} \mathrm{C}$, the serum was used for measurement of renal function and ELISA. Kidney tissues were collected by bilateral nephrectomy. After removing the kidney capsule and perirenal fat, the left kidney tissues were fixed in $10 \%$ neutral formalin at $4^{\circ} \mathrm{C}$ for $24 \mathrm{~h}$ for histopathology, while the right kidney tissues were segmented for gene expression analyses. Animal experimental procedures were approved by the Ethics Committee of Committee of Shanxi Dayi Hospital and conducted in accordance with Guide for the Care and Use of Laboratory Animal.

Hematoxylin and eosin staining $(H \& E)$. The kidney tissues were fixed with $10 \%$ neutral formalin for $<24 \mathrm{~h}$ and then washed with PBS. Mice kidneys were dehydrated with a series of graded ethanol and then embedded in paraffin and sliced into 3- $\mu \mathrm{m}$-thick sections for H\&E. The paraffin-embedded sections were stained with hematoxylin and eosin for $5 \mathrm{~min}$ at room temperature (Beijing Solarbio Science \& Technology Co., Ltd.) and visualized under a light microscope (Leica Microsystems GmbH).

Biochemical index detection. The collected serum was analyzed on the Roche molecular P800 autobiochemical analyzer (Roche Diagnostics $\mathrm{GmbH}$ ). Blood urea nitrogen (BUN) levels were determined using Urease GLDH method, according to Urea Nitrogen Assay kits (Ningbo Purebio Biotechnology Co., Ltd.) and the levels of serum creatinine $(\mathrm{Cr})$ were assayed following the protocol of the Creatinine Detection kits (Whitman Biotechnology Co., Ltd.).
Cell culture and treatment. The renal tubular epithelial HK-2 cells (American Type Culture Collection) were cultured in $5 \% \mathrm{CO}_{2}$ at $37^{\circ} \mathrm{C}$ in a humidified incubator with Dulbecco's modified Eagle's medium (HyClone/Pierce; Thermo Fisher Scientific, Inc.), which was supplemented with $10 \%$ fetal bovine serum (Invitrogen; Thermo Fisher Scientific, Inc.) and $1 \%$ ampicillin. The culture medium was refreshed every 2 days until cell confluence reached $70-80 \%$. Then, the cells were resuspended by digestion with $0.25 \%$ trypsin/EDTA. The cells were exposed to LPS (Sigma-Aldrich; Merck KGaA) in concentrations of $0,0.1,1,10$ and $100 \mu \mathrm{g} / \mathrm{ml}$. A total of $24 \mathrm{~h}$ after LPS exposure, changes in cell viability and inflammation-associated factor levels were assessed to determine appropriate LPS concentration.

Cell transfection. In order to investigate the effects of CD39 on the LPS-induced injury in HK-2 cells, the full-length mouse CD39 in pcDNA3.1 overexpression vector, empty pcDNA3.1 vector (Mock), small interfering RNA of CD39 (siCD39; 5'-GCGATTGTCAGTGAAACTT-3') and small interfering-negative control RNA (siNC; 5'-CCTATCTGGTCA ACACGTATT-3') were obtained by GenePharma (Shanghai GenePharma Co., Ltd). A total of $\sim 4 \times 10^{5}$ HK-2 cells were incubated in each well of 6-well plates with complete medium until the cells reached $70 \%$ confluence. Cell transfection with $50 \mathrm{nmol} / \mathrm{l}$ vector was conducted according to the manufacturer's protocol for Lipofectamine ${ }^{\circledR} 3000$ (Invitrogen; Thermo Fisher Scientific, Inc.). The transfected cells were subjected to $10 \mu \mathrm{g} / \mathrm{ml}$ LPS (Sigma-Aldrich; Merck KGaA) treatment for subsequent experiments. The activity was measured $24 \mathrm{~h}$ after the transfection experiment.

Measurement of cell viability. The cell viability was investigated using Cell Counting Kit-8 (CCK-8; Beyotime Institute of Biotechnology) according to the manufacturer's protocol. All types of transfected cells treated with or without LPS exposure were cultured in 96 -well plates $\left(4 \times 10^{3}\right.$ cells/well). Then, $10 \mu 1$ CCK-8 solution was added to each well and the absorbance was determined using a microplate reader (Bio-Rad Laboratories, Inc.) at a wavelength of $450 \mathrm{~nm}$.

ELISA. The levels of IL-1 $\beta$, IL-18, IL-6 and TNF- $\alpha$ in blood serum and HK-2 cell supernatant were determined using commercially available ELISA kits (cat. nos. H002, H007, H015 and H052; Nanjing Jiancheng Bioengineering Institute). HK-2 cell culture supernatant was collected by a 5-min centrifugation at $10,000 \times \mathrm{g}$ at $4^{\circ} \mathrm{C}$. In all cases, the ELISA was performed according to the manufacturer's protocols. In brief, the ELISA plates were coated with capture antibodies (100 $\mu \mathrm{l} /$ well). The serum or supernatant (serum/supernatant: 1:4) was incubated in the ELISA plate supplemented with the prepared standard liquid. The horseradish peroxidase-labeled antibodies were added into each well and maintained at $37^{\circ} \mathrm{C}$ for $1 \mathrm{~h}$. After the reaction was terminated by phosphoric acid, optical density was determined by a microplate reader at $450 \mathrm{~nm}$ (Biotek, Synergy HT).

Cell apoptosis. For apoptosis analysis, HK-2 cells from each experimental group were stained with Annexin V-fluorescein isothiocyanate (FITC) and propidium iodide (PI) using 
Table I. Primers for reverse transcription-quantitative PCR.

\begin{tabular}{|c|c|c|}
\hline Gene name & Species & Primer sequences \\
\hline \multirow[t]{4}{*}{ NLRP3 } & \multirow[t]{2}{*}{ Mouse } & Forward:5'-AGCTTCAGGTGTTGGAATTAGACA-3' \\
\hline & & Reverse: 5'-GCAGCAAACTGGAAAGGAAG-3' \\
\hline & \multirow[t]{2}{*}{ Human } & Forward: 5'-CTTCTCTGATGAGGCCCAAG-3' \\
\hline & & Reverse: 5'-CGCCACAAAGATGGTCAC-3' \\
\hline \multirow[t]{4}{*}{ CD39 } & \multirow[t]{2}{*}{ Mouse } & Forward: 5'-AGCTGCCCCTTATGGAAGAT-3' \\
\hline & & Reverse: 5'-TCAGTCCCACAGCAATCAAA-3' \\
\hline & \multirow[t]{2}{*}{ Human } & Forward: 5'-AGCAGCTGAAATATGCTGGC-3' \\
\hline & & Reverse: 5'-GAGACAGTATCTGCCGAAGTCC-3' \\
\hline \multirow[t]{4}{*}{ GAPDH } & \multirow[t]{2}{*}{ Mouse } & Forward: 5'-GAACATCATCCCTGCATCCA-3' \\
\hline & & Reverse: 5'-CCAGTGAGCTTCCCGTTCA-3' \\
\hline & \multirow[t]{2}{*}{ Human } & Forward: 5'-CGGAGTCAACGGATTTGGTCGTAT-3' \\
\hline & & Reverse: 5'-AGCCTTCTCCATGGTGGTGAAGAC-3' \\
\hline
\end{tabular}

CD, cluster of differentiation; NLRP3, NLR family pyrin domain containing 3.

Annexin-V-FITC cell apoptosis assay kit (Sigma-Aldrich; Merck $\mathrm{KGaA}$ ) in the dark at $25^{\circ} \mathrm{C}$ for $15 \mathrm{~min}$. Then, apoptosis rate was analyzed under the FACSCalibur flow cytometer (BD Biosciences) equipped with Cell Quest software (version 3.3, BD Biosciences). The proportions of early and late apoptotic cells were counted and compared.

Analysis of reactive oxygen species (ROS). After $24 \mathrm{~h}$ of exposure to LPS, the ROS levels of each type of transfected HK-2 cells was assessed by the 2',7'-dichlorofluorescein diacetate (DCFDA) Cellular Reactive Oxygen Species Detection Assay kit (Abcam). In brief, DCFDA was dissolved in PBS at a final concentration of $20 \mu \mathrm{l} / \mathrm{ml}$. The cells were cultured with DCFDA solution for $30 \mathrm{~min}$ at $37^{\circ} \mathrm{C}$. After being washed with PBS, the levels of ROS were analyzed by flow cytometry (BD Biosciences).

RNA extraction and real time-quantitative PCR (RT-qPCR). Total RNA was extracted from the collected kidney tissues and transfected HK-2 cells using a high-purity total RNA Rapid Extraction kit (BioTeke Corporation). The isolated RNAs $(1 \mu \mathrm{g})$ were mixed with nuclease-free water for cDNA synthesis using a Script cDNA Synthesis kit (Bio-Rad Laboratories, Inc.) at $37^{\circ} \mathrm{C}$ for $15 \mathrm{~min}$ and at $85^{\circ} \mathrm{C}$ for $5 \mathrm{sec}$. RT-qPCR was performed using LightCycler technology (Roche Diagnostics $\mathrm{GmbH}$ ) with FastStart DNA MasterPLUS SYBR-Green I (Roche Diagnostics $\mathrm{GmbH}$ ) detection. The qPCR reaction volume was $20 \mu \mathrm{l}$ and contained template cDNA, $250 \mathrm{nM}$ of each primer, and $4 \mu \mathrm{l}$ of $5 \mathrm{X}$ SYBR-Green Master Mix. The PCR was performed by 50 cycles at $95^{\circ} \mathrm{C}$ for $10 \mathrm{sec}$, at $95^{\circ} \mathrm{C}$ for $10 \mathrm{sec}$, at $60^{\circ} \mathrm{C}$ for $20 \mathrm{sec}$ and at $72^{\circ} \mathrm{C}$ for $30 \mathrm{sec}$. Relative gene expression was normalized to GAPDH and calculated using the $2^{-\Delta \Delta \mathrm{Cq}}$ method (21). All primers are listed in Table I.

Western blot assay. Following treatment, the protein expression in kidney tissues and HK-2 cells was detected by a western blot assay. Total protein was isolated using radioimmunoprecipitation assay lysis buffer (Beyotime Institute of
Biotechnology), following the protocols of the manufacturer. Protein concentrations were quantified using a bicinchoninic protein assay kit (Beyotime Institute of Biotechnology). The lysates $(20 \mu \mathrm{g} / \mathrm{lane})$ were separated on $10 \%$ sodium dodecyl sulfate-polyacrylamide gels and transferred onto polyvinylidene fluoride membranes. Blots were blocked with non-fat milk $(5 \%)$ at room temperature for $2 \mathrm{~h}$ and then incubated with various primary antibodies at $4{ }^{\circ} \mathrm{C}$ overnight. The membranes were then washed and cultured with secondary antibodies (1:2,000; cat. nos. ab205718 and ab205719; Abcam) for $2 \mathrm{~h}$ at room temperature. The blots were detected using enhanced chemiluminescence-plus reagents (GE Healthcare Life Sciences). The relative proteins were normalized to GAPDH. The primary antibodies used in this paper were NLRP3 (1:100; cat. no. ab214185; Abcam), cleaved Caspase-1 (1:1,000; cat. no. ab10836; Abcam) and CD39 (1:1,000; cat. no. ab108248; Abcam).

Statistical analysis. Statistical analysis was performed using GraphPad Prism 6 (GraphPad Software, Inc.). Data were expressed as mean \pm standard error of mean. A Student's t-test was used for analyzing the difference between two groups. One-way analysis of variance followed by Dunnett's t-test was used to calculate the statistical significance between multiple groups. $\mathrm{P}<0.05$ was considered to indicate a statistically significant difference.

\section{Results}

Injection of LPS induces kidney function and pathological changes in mice. To determine kidney function and pathological changes after LPS exposure, kidney tissue sections were subjected to H\&E staining (Fig. 1A). In the control group, the kidney tissues had clear structures without degeneration, atrophy, swelling or necrosis of the renal tubular epithelial cells or inflammatory infiltration. In the LPS group, the kidney tissues showed obvious kidney injury at $12 \mathrm{~h}$. A total of $24 \mathrm{~h}$ after LPS administration, kidney pathological changes were 
A
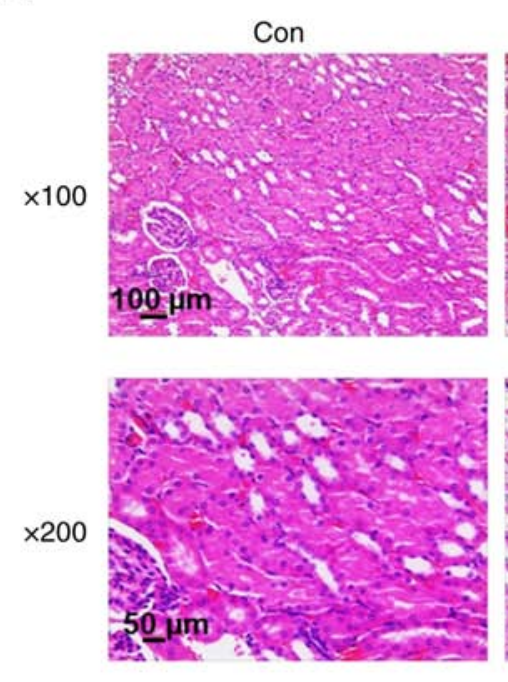

B

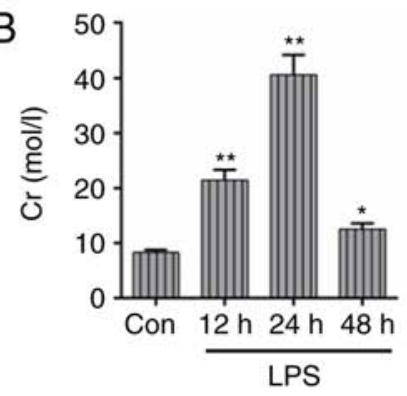

$\mathrm{E}$

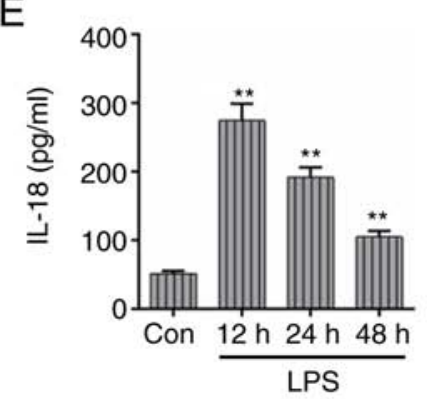

C

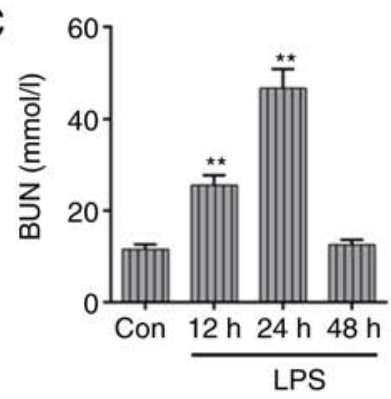

$\mathrm{F}$

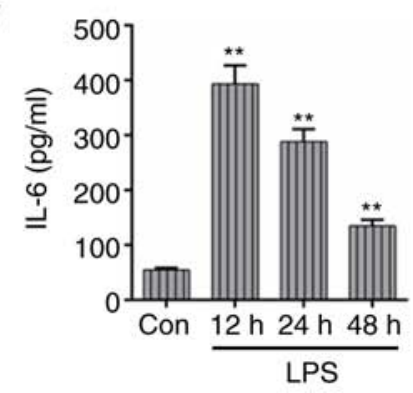

LPS

$12 \mathrm{~h}$
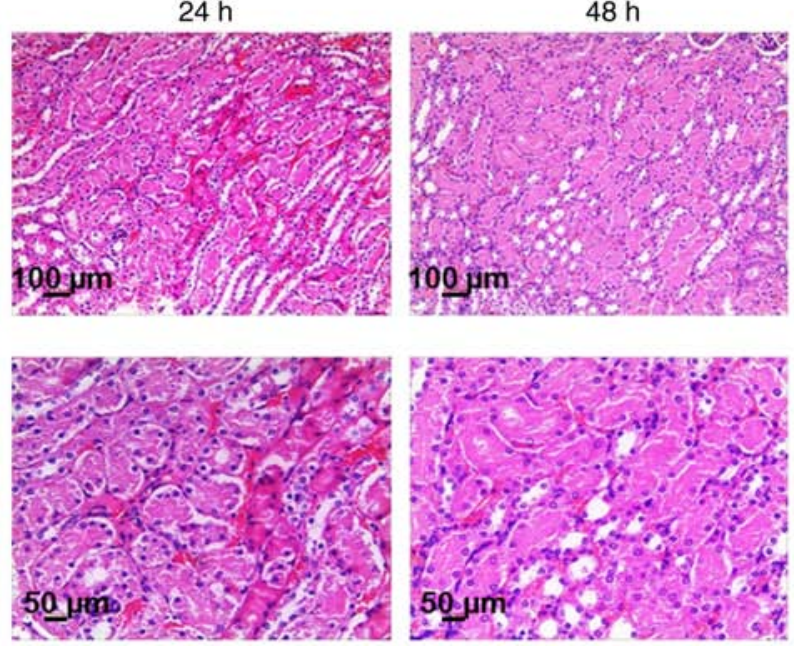

D

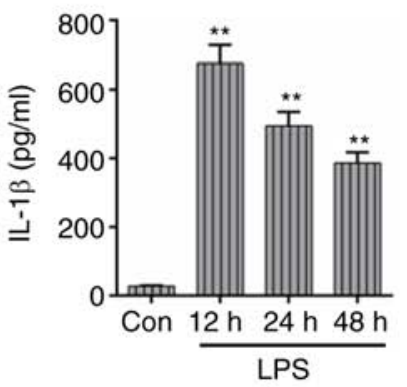

G

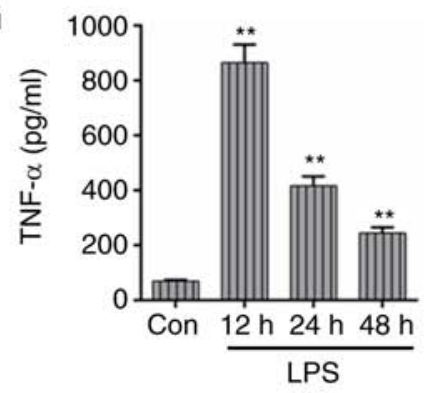

Figure 1. Injection of LPS induces kidney function and pathological changes in mice. In order to determine kidney function and pathological changes after LPS exposure, kidney tissue sections were subjected to H\&E staining and histopathological observation. (A) After LPS treatment, the degree of kidney injury and pathological changes were observed in mice at different time points (12,24 and 48 h). (Magnification: x100 and x200; Scale bar, 100 and $50 \mu \mathrm{m})$. The levels of (B) serum $\mathrm{Cr}$ and (C) BUN in mice analyzed at different time points by the fully automatic biochemical analyzer. The levels of (D) IL-1 $\beta$, (E) IL-18, (F) IL-6 and $(\mathrm{G})$ TNF- $\alpha$ were assessed through the corresponding ELISA kits. Each value represents the mean \pm standard error of the mean $(\mathrm{n}=3)$. ${ }^{*} \mathrm{P}<0.05$ and ${ }^{* * *} \mathrm{P}<0.01$ vs. Con group. IL, interleukin; BUN, blood urea nitrogen; TNF- $\alpha$, tumor necrosis factor- $\alpha$; $\mathrm{Cr}$, creatinine; LPS, lipopolysaccharide; H\&E, hematoxylin and eosin; Con, control.

more significant and were characterized by vacuolar degeneration, luminal narrowing, loss of the brush border, tubule dilation and infiltration of interstitial inflammatory cells. After $48 \mathrm{~h}$, the histopathology of the kidney was improved, however, inflammatory cell infiltration was still observed in the renal interstitium. In addition, as shown in Fig. $1 \mathrm{~B}$ and $\mathrm{C}$, the $\mathrm{Cr}$ and BUN levels in mice were significantly increased within $24 \mathrm{~h}$ after LPS administration $(\mathrm{P}<0.01)$, while both $\mathrm{Cr}$ and BUN levels decreased at $48 \mathrm{~h}$, indicating that the levels of $\mathrm{Cr}$ and BUN were positively correlated with kidney pathological severity.

Moreover, the levels of IL-1 $\beta$, IL-18, IL- 6 and TNF- $\alpha$ peaked at $12 \mathrm{~h}$ and then reduced gradually as the time of LPS administration increased (Fig. 1D-G). However, the levels of these inflammatory cytokines were still much increased compared with the control group. The expression of CD39, inflammasome NLRP3 and cleaved caspase-1 were also measured by RT-qPCR and western blotting. As presented in Fig. 2A, C and D, both NLRP3 mRNA and protein levels increased significantly at $24 \mathrm{~h}$ after LPS injection $(\mathrm{P}<0.01)$ but reduced at $48 \mathrm{~h}$. The expression of CD39 peaked at $12 \mathrm{~h}$ and then continuously reduced at 24 and $48 \mathrm{~h}$ (Fig. 2B, C and F). The changes in protein level of cleaved caspase-1 were consistent with the expression of CD39 (Fig. 2C and E). Taken together, the kidney injury and inflammation were the most serious at $48 \mathrm{~h}$ of LPS administration. 

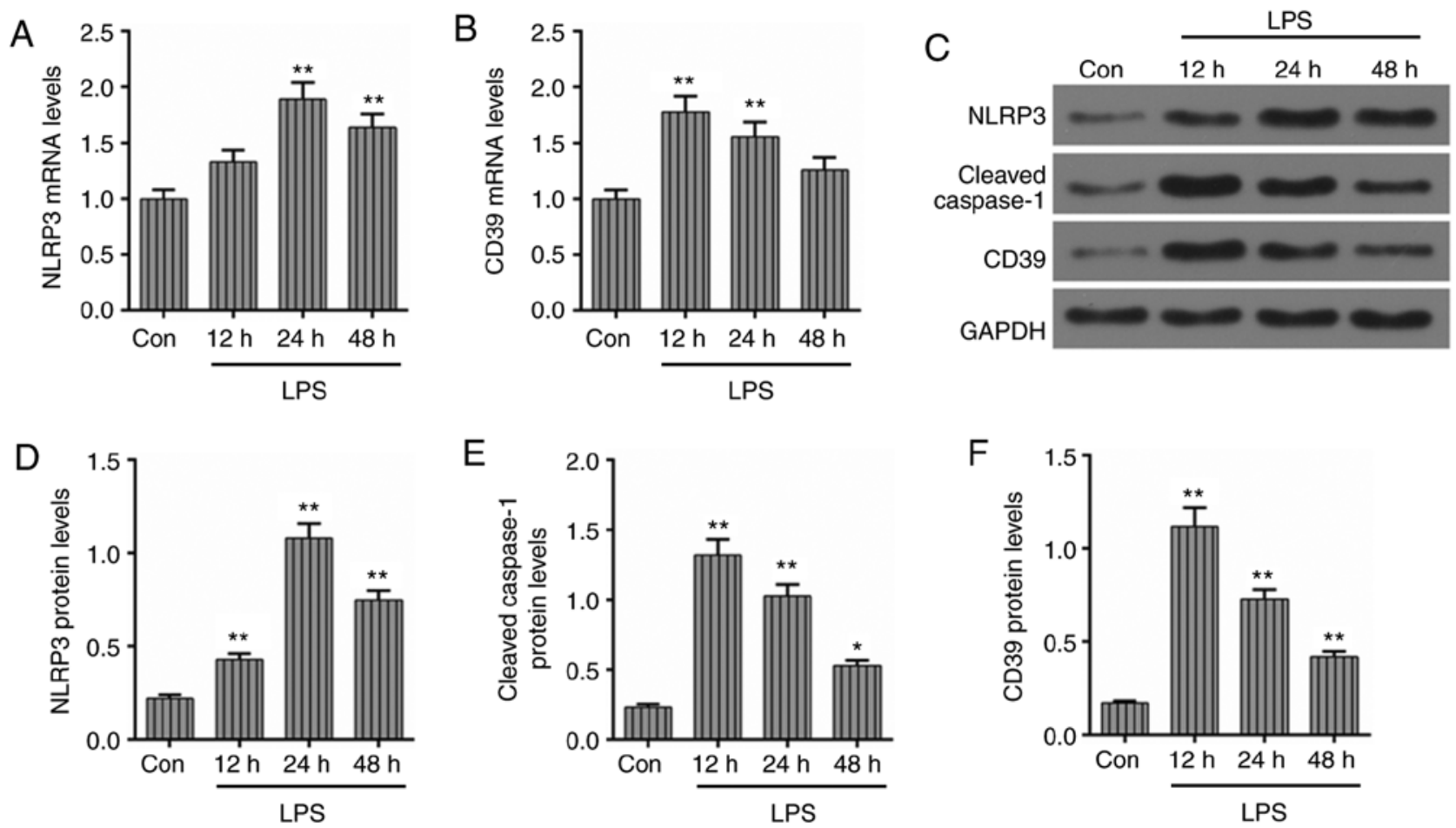

Figure 2. Injection of LPS induces the expression of CD39 and inflammatory cytokines changes in the murine kidney. To study the relationship between CD39 and the inflammatory response, the expression of CD39, the NLRP3 inflammasome and cleaved caspase-1 were detected by RT-qPCR and western blotting. (A) The mRNA levels of NLRP3 were significantly increased at $24 \mathrm{~h}$ and reduced at $48 \mathrm{~h}$ after LPS injection. (B) The expression of CD39 peaked at $12 \mathrm{~h}$ and then continuously reduced at 24 and $48 \mathrm{~h}$. (C) Western blot assay was used to assess the protein levels of NLRP3, cleaved caspase-1 and CD39. The levels of (D) NLRP3, (E) cleaved caspase-1 and (F) CD39 following treatment with different concentrations of LPS. The protein level of cleaved caspase-1 was peaked at $12 \mathrm{~h}$ and then continuously reduced at 24 and $48 \mathrm{~h}$. Each value represents the mean \pm standard error of the mean $(\mathrm{n}=3)$. GAPDH served as an internal control. " $\mathrm{P}<0.05$ and ${ }^{* *} \mathrm{P}<0.01$ vs. Con group. RT-qPCR, reverse transcription-quantitative PCR; LPS, lipopolysaccharide; NLRP3, NLR family pyrin domain containing $3 ; \mathrm{CD}$, cluster of differentiation; Con, control.

Concentration of LPS shows a positive association with the expression of inflammatory mediators in $\mathrm{HK}-2$ cells. To determine an optimal LPS concentration for subsequent experiment, HK-2 cells were treated with a series of concentrations $(0,0.1$, 1,10 and $100 \mu \mathrm{g} / \mathrm{ml}$ ) of LPS. As shown in Fig. 3A, the HK-2 cell viability was gradually decreased as the concentration of LPS increased and reduced significantly when the cells were treated with $10 \mu \mathrm{g} / \mathrm{ml}$ LPS $(\mathrm{P}<0.01)$. As listed in Fig. 3B-E, the inflammatory cytokines (IL-1 $\beta$, IL-18, IL-6 and TNF- $\alpha$ ) showed a positive association with the concentration of LPS. The treatment of LPS $(1 \mu \mathrm{g} / \mathrm{ml})$ was enough to cause a significant inflammation in HK-2 cells $(\mathrm{P}<0.01)$. Furthermore, the expression of NLRP3 and cleaved caspase-1 was increased under the treatment of $10 \mu \mathrm{g} / \mathrm{ml}$ LPS (Fig. 3F and H-J). Meanwhile, the concentration of $0.01 \mu \mathrm{g} / \mathrm{ml}$ LPS slightly affected the expression of CD39. However, $1 \mu \mathrm{g} / \mathrm{ml}$ LPS could induce an increase of the CD39 expression levels and both its mRNA and protein levels, which then decreased as the concentrations of LPS increased (Fig. 3G, H and K). Together, the concentration of LPS was positively correlated with the level of inflammation, while the expression of CD39 increased slightly under a low concentration of LPS but gradually decreased as the LPS concentration increased.

Overexpression of CD39 could mitigate LPS-induced inflammation and apoptosis in HK-2 cells. In order to study the functional effects of CD39 on the LPS-induced inflammation and apoptosis in HK-2 cells, the CD39 overexpression vector was constructed and transfected into HK-2 cells. As Fig. 4A shows, the CD39 vector was expressed stably in HK-2 cells. The CCK-8 assay showed that the cell viability in LPS + Mock group was significantly reduced in comparison with the Mock group, while the transfection of CD39 could enhance the HK-2 cell viability $(\mathrm{P}<0.01$; Fig. $4 \mathrm{~B})$. In addition, the treatment of LPS could induce strong inflammation, as the levels of IL-1 $\beta$, IL-18, IL-6 and TNF- $\alpha$ were significantly increased in the LPS group, however, increasing CD39 expression could effectively inhibit the levels of these inflammatory cytokines $(\mathrm{P}<0.01$; Fig. 4C-F). The apoptosis and ROS level was also measured by flow cytometry. As shown in Fig. $4 \mathrm{G}$ and H, the apoptosis rate and ROS level significantly increased following LPS administration $(\mathrm{P}<0.01)$, while transfection of $\mathrm{CD} 39$ had the ability to decrease the apoptosis rate and ROS level. Therefore, the results of the present study indicated that elevated CD39 may contribute to the mitigation of the LPS-induced injury, inflammation and ROS accumulation in HK-2 cells.

Overexpressed CD39 could inhibit the activation of the inflammasome in HK-2 cells. As mentioned earlier, the overexpression of CD39 could significantly inhibit the LPS-induced inflammation in HK-2 cells. After transfection of CD39, the expression of NLRP3, which works as an inflammasome and whose activation serves an essential role in increasing inflammatory cytokines, was measured. As indicated in Fig. 5A, the expression of NLRP3 was increased under LPS administration, while the transfection of CD39 overexpression could 
A
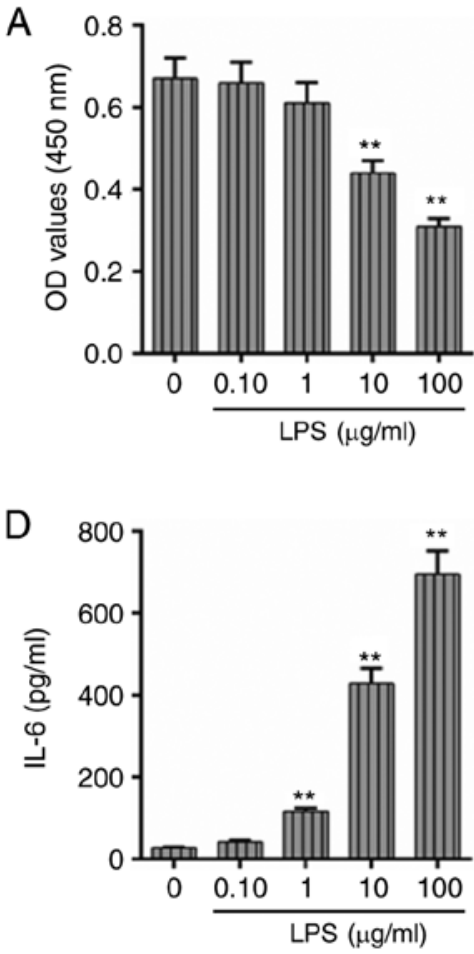

B
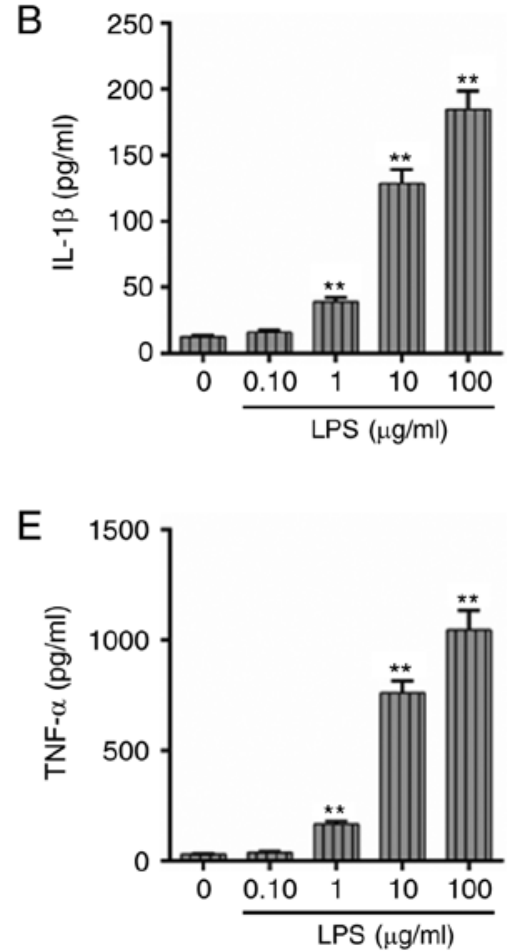

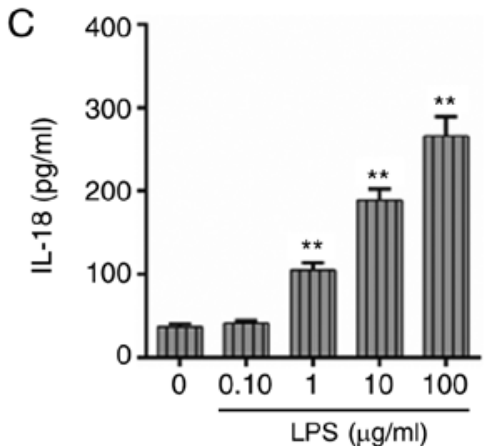

F

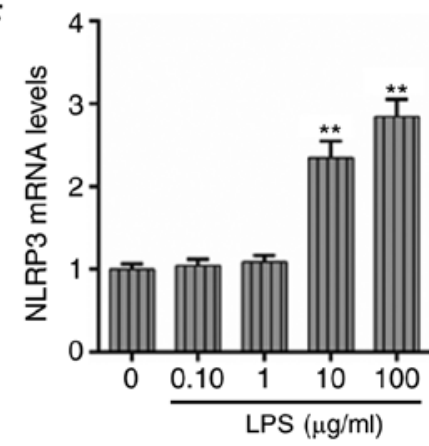

G

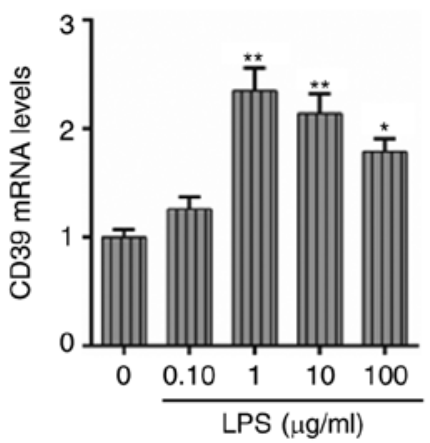

$\mathrm{H}$

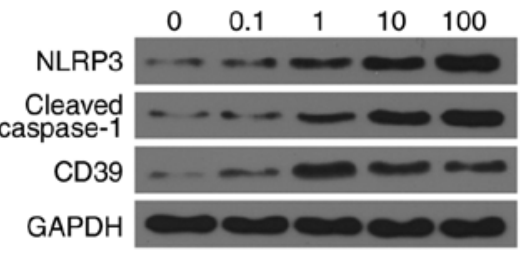

I
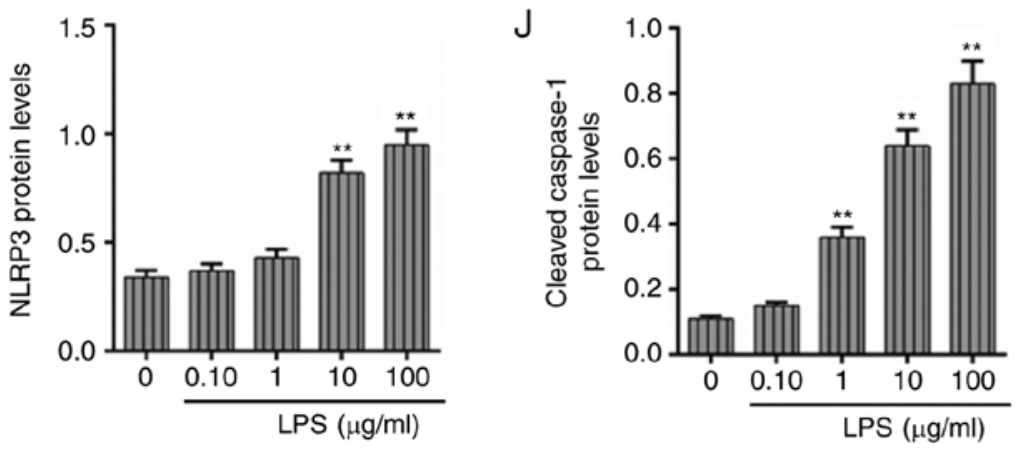

K

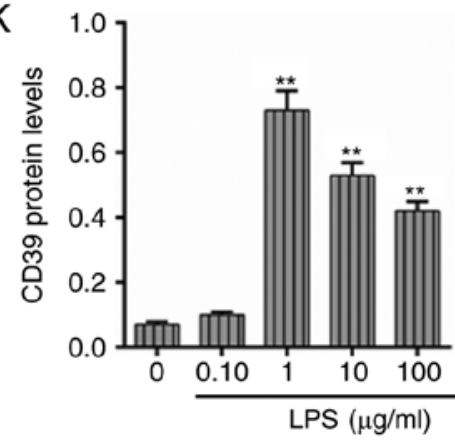

Figure 3. Concentration of LPS shows a positive association with the expression of inflammatory mediators in HK-2 cells. To study the effects of LPS treatment at a series of concentrations $(0,0.1,1,10$ and $100 \mu \mathrm{g} / \mathrm{ml})$ on HK-2 cells, the cell viability, inflammation-associated factors and CD39 expression were measured after LPS treatment. (A) The cell viability was examined using a Cell Counting Kit- 8 assay. The levels of (B) IL-1 $\beta$, (C) IL-18, (D) IL-6 and (E) TNF- $\alpha$ were measured under the different concentrations of LPS by corresponding ELISA kits. The mRNA levels of (F) NLRP3 and (G) CD39 were determined by RT-qPCR. (H) Western blot assay was used to assess the protein levels of (I) NLRP3, $(J)$ cleaved caspase-1 and (K) CD39. Each value represents mean \pm standard error of the mean ( $\mathrm{n}=3$ ). GAPDH served as an internal control. ${ }^{*} \mathrm{P}<0.05$ and $^{* *} \mathrm{P}<0.01$ vs. Con group. RT-qPCR, reverse transcription-quantitative PCR; NLRP3, NLR family pyrin domain containing 3; IL, interleukin; TNF- $\alpha$, tumor necrosis factor- $\alpha$; LPS, lipopolysaccharide; CD, cluster of differentiation; OD, optical density; Con, control.

significantly inhibit LPS-induced increased NLRP3 level. The transfection of CD39 induced a significant upregulation of CD39 mRNA, compared with LPS + Mock group $(\mathrm{P}<0.01$; Fig. 5B). The changes of their protein levels are shown in Fig. 5C-F. The protein levels of NLRP3 and CD39 were basically consistent with their mRNA levels. In comparison to the LPS + Mock group, the protein level of cleaved caspase-1 was significantly reduced after the transfection with CD39 overexpression $(\mathrm{P}<0.01)$. Therefore, these results suggested that the inhibitory effects of CD39 overexpression 

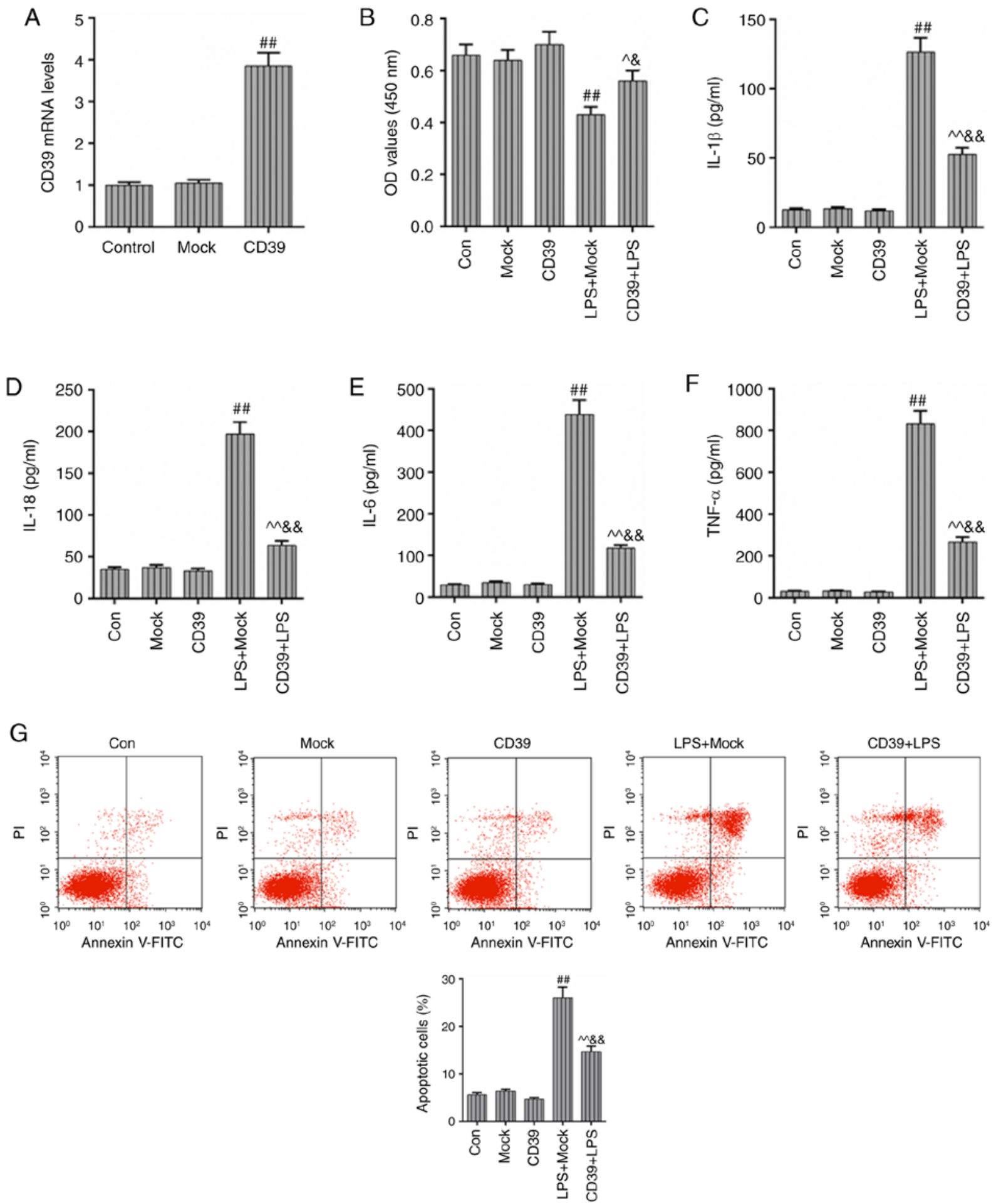

Figure 4. Overexpression of CD39 could mitigate LPS-induced inflammation and apoptosis in HK-2 cells. In order to study the functional effects of CD39 on the LPS-induced inflammation and apoptosis in HK-2 cells, the CD39 overexpression vector was constructed and transfected into HK-2 cells before LPS administration. (A) The transfection efficiency of CD39 overexpression vector was measured by RT-qPCR. (B) The effects of CD39 transfection on the HK-2 cell viability were assessed by Cell Counting Kit-8 assay under LPS administration. The effects of CD39 transfection on (C) IL-1 $\beta$, (D) IL-18, (E) IL-6 and (F) TNF- $\alpha$ levels were detected under LPS treatment. (G) The effects of CD39 transfection on the apoptosis rate were assessed by flow cytometry.

on LPS-induced inflammation may rely on suppressing the activation of NLRP3.

CD39 inhibition aggravates LPS-induced inflammation and cell apoptosis in $H K-2$ cells. In order to further verify the protective effects of CD39 on the HK-2 cells under the treatment of LPS, the siCD39 vector was transfected into HK-2 cells and the levels of inflammation and apoptosis rate were detected. Fig. 6A demonstrated that the expression of CD39 was effectively inhibited by siRNA in HK-2 cells. LPS treatment could induce the reduced cell viability, while the transfection of siCD39 could further decrease cell viability, compared with the LPS + NC group $(\mathrm{P}<0.05$; Fig. $6 \mathrm{~B})$. The levels of those inflammatory cytokines (IL-1 $\beta$, IL-18, IL-6 and TNF- $\alpha$ ) are shown in Fig. 6C-F, 

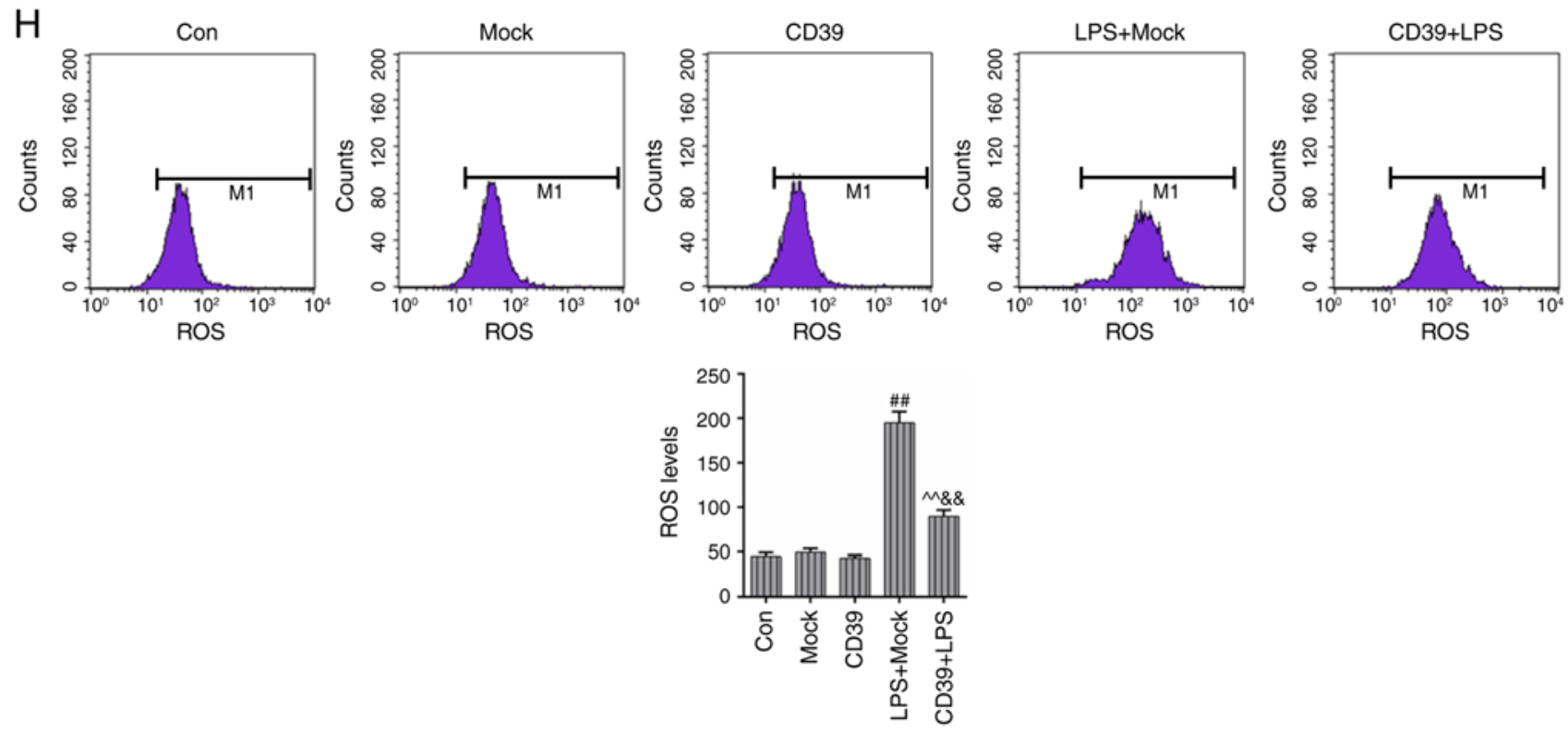

Figure 4. Continued. (H) The effects of CD39 transfection on the ROS level were assessed by flow cytometry. Each value represents the mean \pm standard error of the mean $(\mathrm{n}=3)$. GAPDH served as an internal control. ${ }^{\# \#} \mathrm{P}<0.01$ vs. Mock group; ${ }^{\wedge} \mathrm{P}<0.05$ and ${ }^{\wedge} \wedge \mathrm{P}<0.01$ vs. LPS + Mock group; ${ }^{\text {\& }} \mathrm{P}<0.05$ and ${ }^{\text {\&\& }} \mathrm{P}<0.01$ vs. CD39 group. TNF- $\alpha$, tumor necrosis factor- $\alpha$; RT-qPCR, reverse transcription-quantitative PCR; IL, interleukin; LPS, lipopolysaccharide; ROS, reactive oxygen species.

A
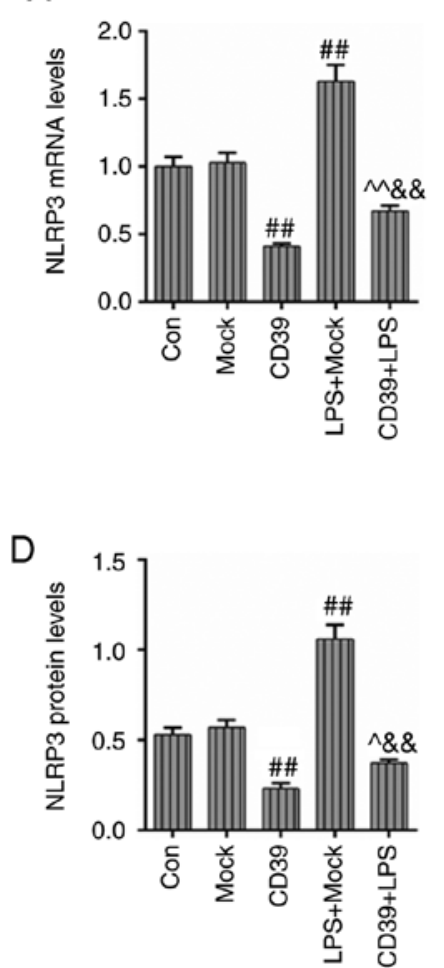

B

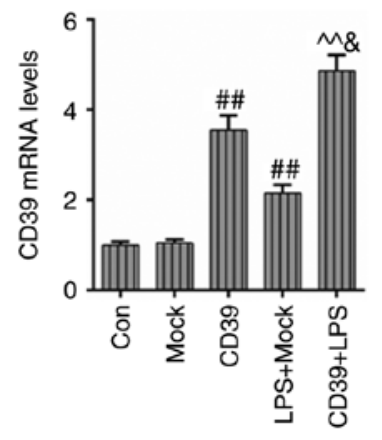

E

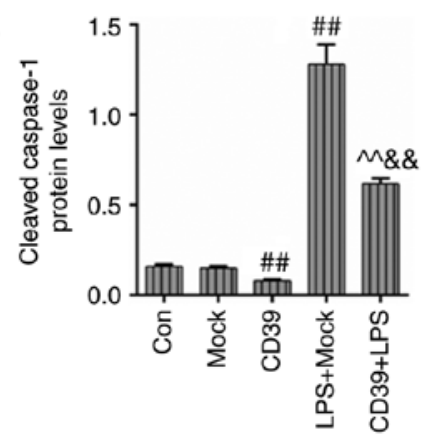

C

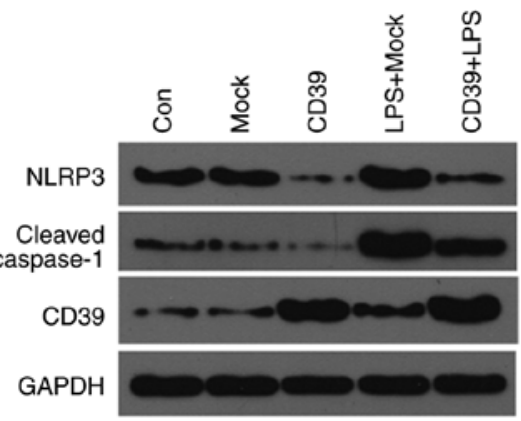

$\mathrm{F}$

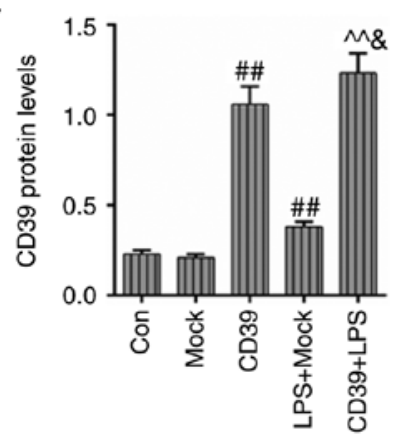

Figure 5. Overexpressed CD39 could inhibit the activation of the inflammasome in HK-2 cells. To further investigate the mechanism of CD39 overexpression suppressing LPS-induced inflammation in HK-2 cells, the expression of NLRP3 and cleave caspase-1 were measured. The effects of CD39 overexpression on the mRNA levels of (A) NLRP3 and (B) CD39 were detected by RT-qPCR after LPS treatment. (C) Western blotting was used to measure the effects of CD39 overexpression on the protein levels of (D) NLRP3, (E) cleaved caspase-1 and (F) CD39 after LPS treatment. Each value represents the mean \pm standard error of the mean $(\mathrm{n}=3)$. GAPDH served as an internal control. ${ }^{\# \#} \mathrm{P}<0.01$ vs. Mock group; $\wedge \mathrm{P}<0.05$ and ${ }^{\wedge} \wedge \mathrm{P}<0.01$ vs. LPS $+\mathrm{Mock}$ group; ${ }^{\&} \mathrm{P}<0.05$ and ${ }^{\&} \& \mathrm{P}<0.01$ vs CD39 group. NLRP3, NLR family pyrin domain containing 3; CD, cluster of differentiation; RT-q, reverse transcription-quantitative; LPS, lipopolysaccharide.

and it was observed that the transfection of siCD39 aggravated the inflammation caused by LPS treatment. The levels of IL-1 $\beta$,
IL-18 and IL-6 in LPS + siCD39 group were significantly increased compared with those in LPS + NC group $(\mathrm{P}<0.05)$, 
A

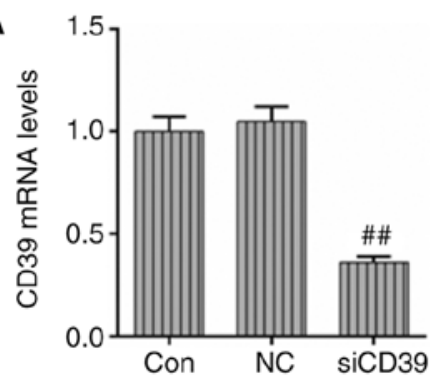

$\mathrm{B}$
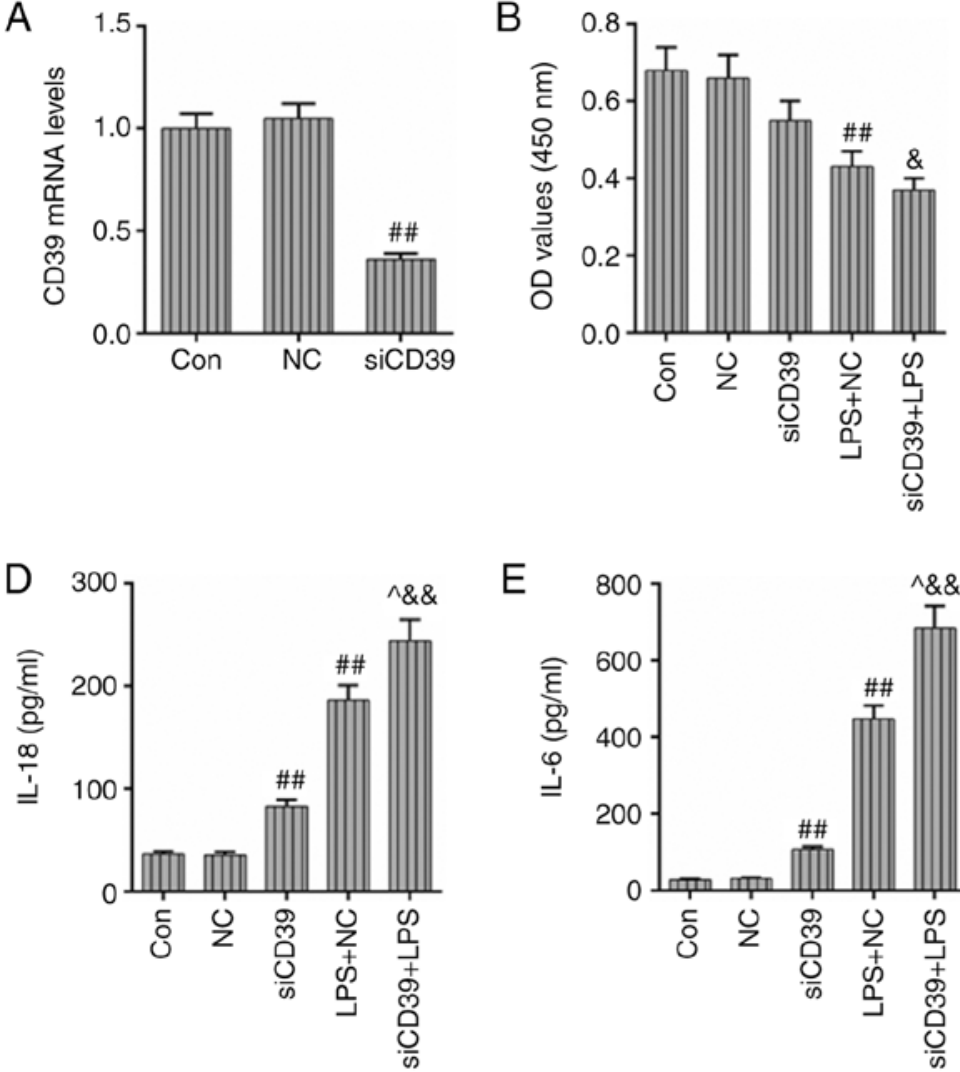

E

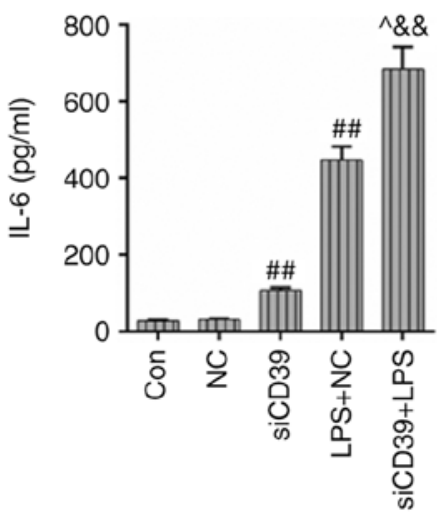

C
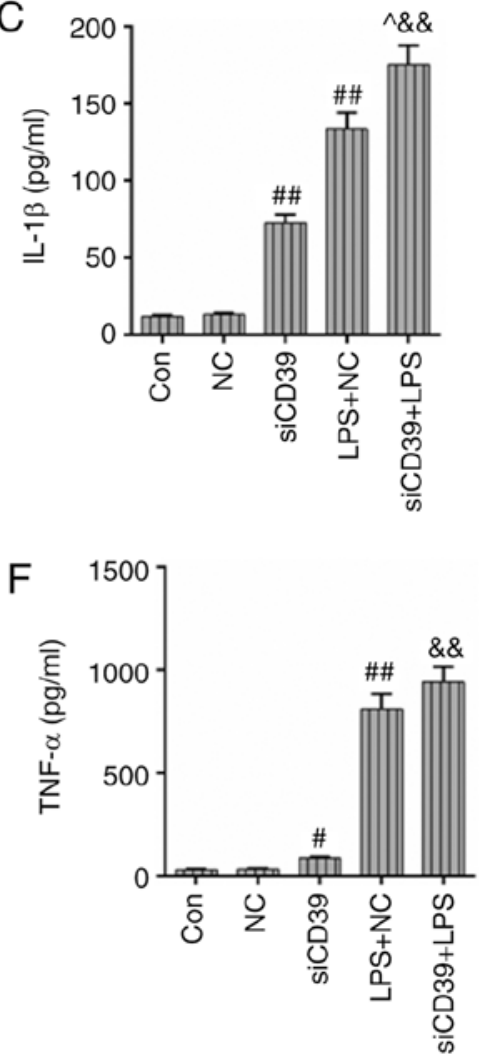
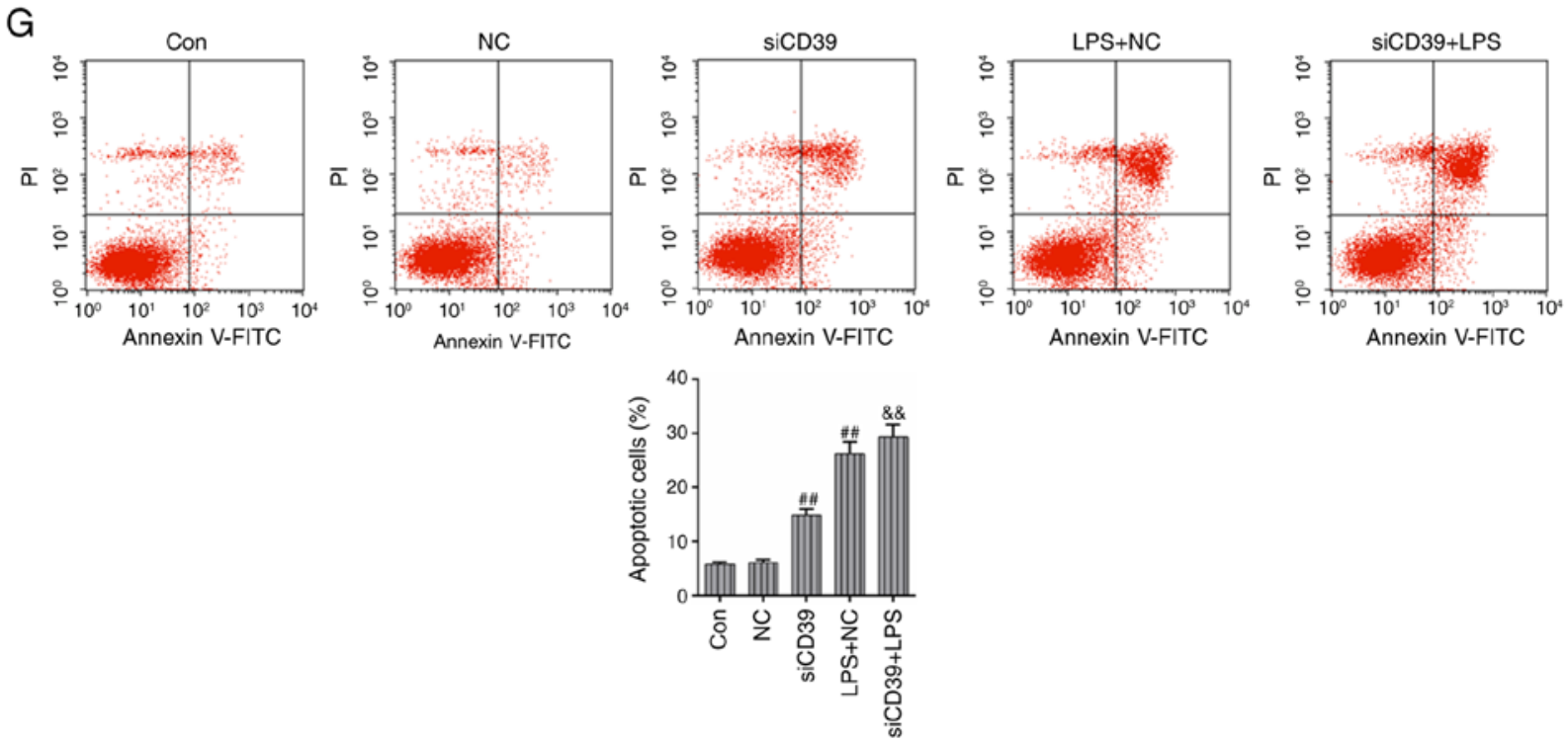

Figure 6. Transfection of siCD39 aggravates LPS-induced inflammation and cell apoptosis in HK-2 cells. The siCD39 vector was transfected into HK-2 cells and then, the levels of inflammation and apoptosis rate were determined. (A) The transfection efficiency of the siCD39 vector was assessed by RT-qPCR. (B) The effects of siCD39 transfection on the HK-2 cell viability were assessed by Cell Counting Kit-8 assay after the LPS treatment. The effects of siCD39 on the levels of inflammatory cytokines (C) IL-1 $\beta$, (D) IL-18, (E) IL-6 and (F) TNF- $\alpha$ were detected by the corresponding ELISA kits. (G) The effects of CD39 inhibition on the apoptosis rate were assessed by flow cytometry.

while the TNF- $\alpha$ level was increased slightly. In addition, compared with cells transfected with the NC vector, the apoptosis rate and ROS level both had a slight increase in the cells transfected with siCD39 after LPS treatment (Fig. 6G and H). Collectively, the results of the present study indicated that in contrast to CD39 overexpression, the transfection of siCD39 could aggravate LPS-induced inflammation, cell apoptosis and ROS accumulation in HK-2 cells.
CD39 inhibition has a promoting effect on the activation of the inflammasome in $\mathrm{HK}-2$ cells. After transfection with siCD39, the NLRP3 mRNA levels were increased again, compared with the LPS + NC group (Fig. 7A). In the meantime, the transfection of siCD39 obviously decreased the expression of CD39 and further weakened the stress reaction of CD39 to LPS treatment $(\mathrm{P}<0.01$; Fig. $7 \mathrm{~B})$. The protein levels of NLRP3 and CD39 were basically consistent with 

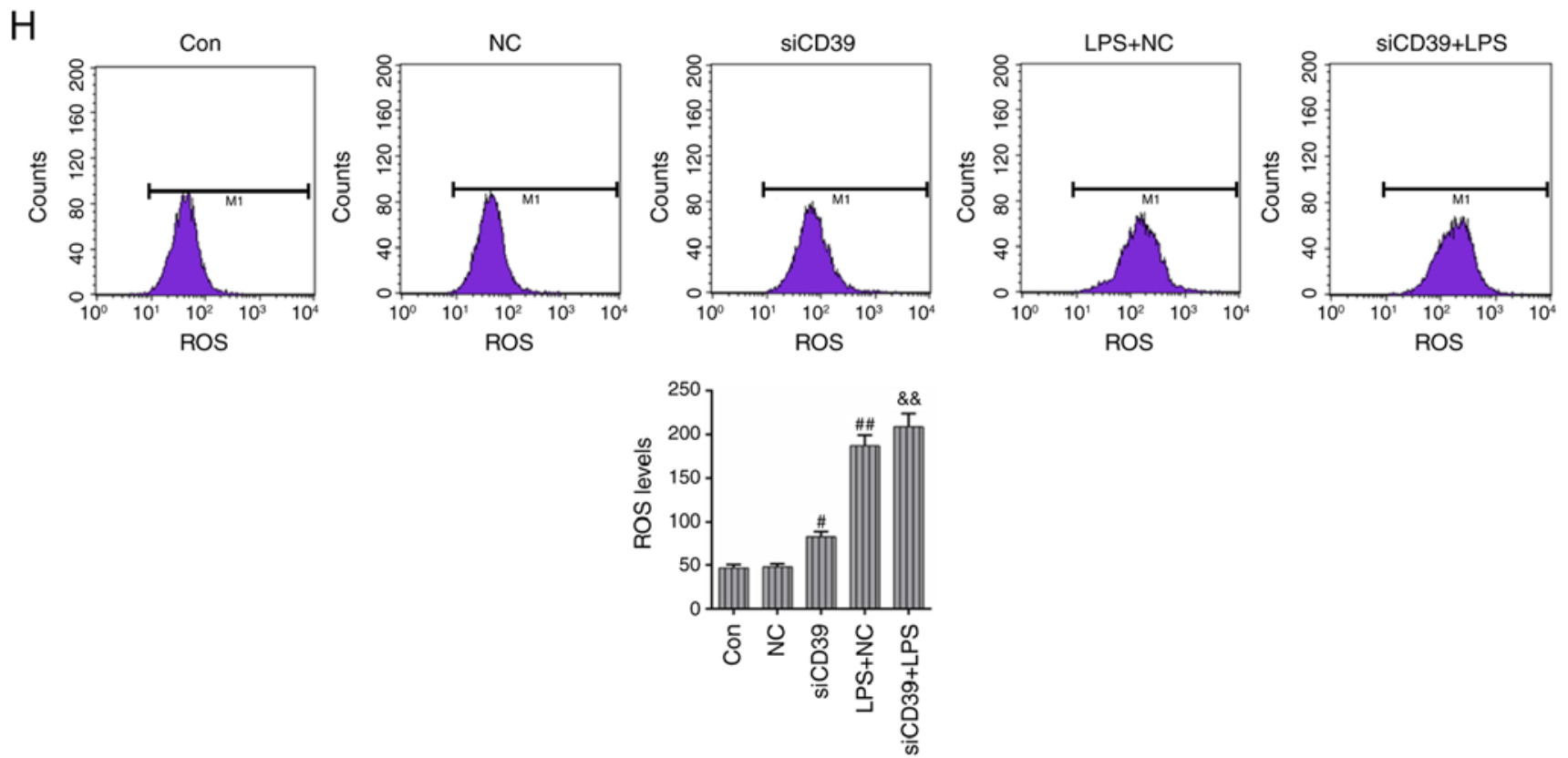

Figure 6. Continued. $(\mathrm{H})$ The effects of CD39 inhibition on the ROS level were assessed by flow cytometry. Each value represents the mean \pm standard error of the mean $(n=3)$. GAPDH served as an internal control. ${ }^{~} \mathrm{P}<0.05$ and ${ }^{\# \#} \mathrm{P}<0.01$ vs. NC group; $\wedge \mathrm{P}<0.05$ vs. LPS $+\mathrm{NC}$ group; ${ }^{\&} \mathrm{P}<0.05$ and ${ }^{\text {\& }} \mathrm{P}<0.01$ vs. siCD39 group. ROS, reactive oxygen species; CD39 siRNA, cluster of differentiation small interfering RNA; IL, interleukin; TNF- $\alpha$, tumor necrosis factor- $\alpha$; RT-qPCR, reverse transcription-quantitative PCR; LPS, lipopolysaccharide; NC, negative control; CD, cluster of differentiation.
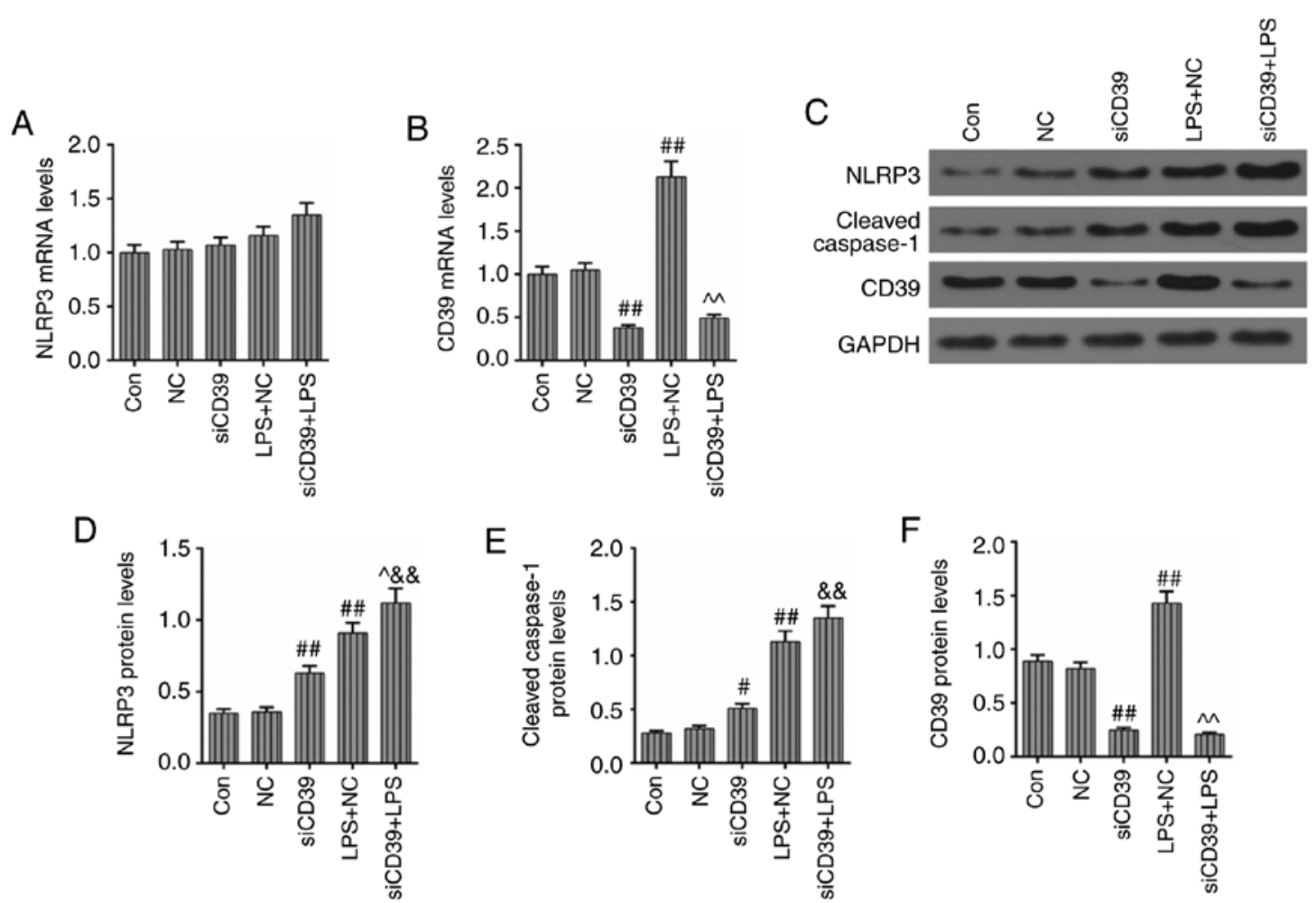

Figure 7. CD39 inhibition has a promoting effect on the activation of the inflammasome in HK-2 cells. In order to further verify the protective effects of CD39 on the HK-2 cells under treatment of LPS, the siCD39 vector was transfected into HK-2 cells, then the expression of NLRP3 and cleaved caspase-1 were determined. The effects of CD39 inhibition on the mRNA levels of (A) NLRP3 and (B) CD39 were detected by RT-qPCR after LPS treatment. (C) Western blotting and the quantification of the effects of siCD39 on the protein levels of (D) NLRP3, (E) cleaved caspase-1 and (F) CD39 after LPS treatment. Each value represents the mean \pm standard error of the mean $(\mathrm{n}=3)$. GAPDH served as an internal control. ${ }^{\|} \mathrm{P}<0.05,{ }^{\# \#} \mathrm{P}<0.01$ vs. $\mathrm{NC}$ group; ${ }^{\wedge} \mathrm{P}<0.05$ and ${ }^{\wedge} \wedge \mathrm{P}<0.01$ vs. LPS + NC group; \&\& $\mathrm{P}<0.01$ vs. siCD39 group. NLRP3, NLR family pyrin domain containing 3; LPS, lipopolysaccharide; CD, cluster of differentiation; si, small interfering; RT-qPCR, reverse transcription-quantitative PCR.

their mRNA levels, and the cleaved caspase-1 protein level had a slight upregulation under the effects of CD39 inhibition and LPS treatment (Fig. 7C-F). The results of the present study suggested that the inhibition of CD39 may promote the 
activation of NLRP3 and subsequent inflammation in HK-2 cells.

\section{Discussion}

Results obtained in this study revealed a protective role for CD39 in LPS-induced inflammation and injury in HK-2 cells. LPS stimulation could cause the activation of the inflammatory response, which is an integral part of innate immunity. However, an excessive inflammatory response can lead to severe tissue injury, acute organ failure or chronic inflammatory conditions $(22,23)$. The previous study has demonstrated that the mechanism of CD39 in macrophages regulating adaptive immunity involves the control of NLRP3 inflammasome activation (24). This study investigated changes of CD39 expression level in the murine kidney after LPS intraperitoneal injection and found that CD39 had a stressed upregulation at the beginning of LPS administration and then decreased as the inflammation severity became greater, meanwhile, the expression of NLRP3 was increased. In order to further study the potential relationship between NLRP3 and CD39, the levels of NLRP3 and inflammation-associated factors under the effects of CD39 overexpression and inhibition were detected in vitro. The results of the present study indicated that overexpressed CD39 could negatively regulate the activation of NLRP3 and its downstream signaling, therefore decreasing cell apoptosis and ROS accumulation in HK-2 cells.

The NLRP3 inflammasome-mediated inflammatory system has been demonstrated to participate in a number of regulatory mechanisms such as the secretion of pro-inflammatory cytokines, pyroptosis, ROS accumulation and mitochondria damage and autophagy $(25,26)$. The overactive NLRP3 inflammasome was reported to be closely associated with multiple inflammatory diseases $(27,28)$ including sepsis (29). A previous study showed that upregulated CD39 during abdominal sepsis could inhibit the NLRP3 activation and diminish inflammation, ultimately improving the survival of septic mice (30). In the present study, the transfection of CD39 overexpression also could inhibit the expression and activity of NLRP3, and subsequently improve survival of HK-2 cells. In this study, it was observed that the elevated CD39 could inhibit the cell apoptosis and ROS accumulation in HK-2 cells. When cells were stimulated by extracellular medium, the damaged mitochondria released mitochondrial (mt)ROS into the cytoplasm, which then induced the activation of NLRP3, resulting in the secretion of cleaved caspase- 1 and several pro-inflammatory cytokines (31). A recent study demonstrated that mtROS was upstream from NLRP3 and that the treatment with an mtROS inhibitor could effectively induce a reduction of NLRP3 expression (32). Similarly, Celastrol was reported to inhibit the activation of the NLRP3 inflammasome and ameliorate inflammation by reducing ROS production (33). Combined with these studies, the present study suggested that CD39 overexpression suppressing the expression and activity of NLRP3 may also partially rely on the inhibition of ROS accumulation.

Intracellular ATP works as the molecular unit of currency of energy transfer (34), however, cell injury could induce the secretion of ATP into the extracellular space where the extracellular ATP (eATP) acts as a 'warning signal'. A study revealed that eATP could contribute to the activation of the P2X purinoceptor 7 and initiate inflammation (35). In 2017, Savio et al (20) indicated that the CD39 protein impeded the NLRP3 activation and subsequent pro-inflammatory cytokines through scavenging eATP, ultimately inhibiting systemic inflammation and contributing to liver homeostasis restoration. In general, the level of eATP was under the careful control of CD39 (36), however, the present study indicated that the functional effects of CD39 were gradually decreased as the inflammation severity increased. The downregulated CD39 may have less control over eATP level, which could cause a vicious circle as the inflammation was aggravated, therefore promoting cell injury. Moreover, a previous study demonstrated that CD39 could effectively improve survival of sepsis via decreasing systemic inflammation (30). Compared with that, the results of the present study provided more details about the underlying mechanisms of the positive effects of CD39 on protecting the kidney from LPS-induced septic organ injury. In the septic HK-2 cell injury induced by LPS, NLRP-3-related inflammatory pathway was over-activated. Additionally CD39 overexpression/inhibition could affect the NLRP3-related inflammatory pathway, cell apoptosis and cell cycle arrest in HK-2 cells. The present study revealed a high association between the anti-septic ability of CD39 and the repression of the NLRP3-related inflammatory pathway in septic AKI. Taken together, the present study indicated that overexpressed CD39 could diminish the expression and activity of NLRP3 and subsequent secretion of pro-inflammatory cytokines, however, whether the protective ability of CD39 involves the control of eATP remains to be further investigated.

In conclusion, the present study indicated that CD39 had a promoting effect on the ability of renal tubular epithelial cells to resist LPS-induced damage. The enhanced CD39 improved cell viability and apoptosis, diminished the activation of NLRP3 and mediated inflammatory system through impeding the overproduction of ROS. In addition, considering the close relationship between CD39 and eATP, the authors also speculated that the protective ability of CD39 in renal tubular epithelial cells was also mediated through the control of eATP, however, further experiments are needed to validate the hypothesis. Therefore, CD39 might be a potential therapeutic target in sepsis-induced AKI.

\section{Acknowledgements}

Not applicable.

\section{Funding}

No funding was received.

\section{Availability of data and materials}

The analyzed datasets generated during the study are available from the corresponding author on reasonable request.

\section{Authors' contributions}

Substantial contributions to conception and design: MY. Data acquisition, data analysis and data interpretation: ZK, YW, LL and TM. Drafting the article or critically revising it for important intellectual content: MY. Final approval of the version to be published: All authors. Agreement to be accountable for 
all aspects of the work in ensuring that questions related to the accuracy or integrity of the work are appropriately investigated and resolved: All authors.

\section{Ethics approval and consent to participate}

Animal experimental procedures were approved by the Ethics Committee of Committee of Shanxi Dayi Hospital (Taiyuan, China) and conducted in accordance with Guide for the Care and Use of Laboratory Animal.

\section{Patient consent for publication}

Not applicable.

\section{Competing interests}

The authors declare that they have no conflicts of interest.

\section{References}

1. Angus DC and van der Poll T: Severe sepsis and septic shock. N Engl J Med 369: 2063, 2013.

2. Aziz M, Jacob A, Yang WL, Matsuda A and Wang P: Current trends in inflammatory and immunomodulatory mediators in sepsis. J Leukoc Biol 93: 329-342, 2013.

3. Hoste EA, Bagshaw SM, Bellomo R, Cely CM, Colman R, Cruz DN, Edipidis K, Forni LG, Gomersall CD, Govil D, et al: Epidemiology of acute kidney injury in critically ill patients: The multinational AKI-EPI study. Intensive Care Med 41: 1411-1423, 2015.

4. Khwaja A: KDIGO clinical practice guidelines for acute kidney injury. Nephron Clin Pract 120: c179-c184, 2012.

5. Alobaidi R, Basu RK, Goldstein SL and Bagshaw SM: Sepsisassociated acute kidney injury. Semin Nephrol 35: 2-11, 2015.

6. Cruz DN, Bolgan I, Perazella MA, Bonello M, de Cal M, Corradi V, Polanco N, Ocampo C, Nalesso F, Piccinni P, et al: North east italian prospective hospital renal outcome survey on acute kidney injury (NEiPHROS-AKI): Targeting the problem with the RIFLE criteria. Clin J Am Soc Nephrol 2: 418-425, 2007.

7. Mayeux PR and MacMillan-Crow LA: Pharmacological targets in the renal peritubular microenvironment: Implications for therapy for sepsis-induced acute kidney injury. Pharmacol Ther 134: 139-155, 2012.

8. Langenberg C, Bellomo R, May C, Wan L, Egi M and Morgera S: Renal blood flow in sepsis. Crit Care 9: R363-R374, 2005.

9. Schrier RW and Wang W: Acute renal failure and sepsis. N Engl J Med 351: 159-169, 2004.

10. Takasu O, Gaut JP, Watanabe E, To K, Fagley RE, Sato B, Jarman S, Efimov IR, Janks DL, Srivastava A, et al: Mechanisms of cardiac and renal dysfunction in patients dying of sepsis. Am J Respir Crit Care Med 187: 509-517, 2013.

11. Dong W, Li Z, Chen Y, Zhang L, Ye Z, Liang H, Li R, Xu L, Zhang B, Liu S, et al: Necrostatin-1 attenuates sepsis-associated acute kidney injury by promoting autophagosome elimination in renal tubular epithelial cells. Mol Med Rep 17: 3194-3199, 2018.

12. De Backer D, Creteur J, Preiser JC, Dubois MJ and Vincent JL: Microvascular blood flow is altered in patients with sepsis. Am J Respir Crit Care Med 166: 98-104, 2002.

13. Cen C, Aziz M, Yang WL, Zhou M, Nicastro JM, Coppa GF and Wang P: Milk fat globule-epidermal growth factor-factor VIII attenuates sepsis-induced acute kidney injury. J Surg Res 213 . 281-289, 2017.

14. Mir SM, Ravuri HG, Pradhan RK, Narra S, Kumar JM, Kuncha M, Kanjilal S and Sistla R: Ferulic acid protects lipopolysaccharide-induced acute kidney injury by suppressing inflammatory events and upregulating antioxidant defenses in $\mathrm{Balb} / \mathrm{c}$ mice. Biomed Pharmacother 100: 304-315, 2018.

15. Eltzschig HK, Sitkovsky MV and Robson SC: Purinergic signaling during inflammation. N Engl J Med 367: 2322-2333, 2012.

16. Yan J, Li Y, Yang H, Zhang L, Yang B, Wang M and Li Q: Interleukin-17A participates in podocyte injury by inducing IL-1 $\beta$ secretion through ROS-NLRP3 inflammasome-caspase-1 pathway. Scand J Immunol 87: e12645, 2018.
17. Yao ST, Cao F, Chen JL, Chen W, Fan RM, Li G, Zeng YC, Jiao S, Xia XP, Han C and Ran QS: NLRP3 is required for complement-mediated caspase-1 and IL-1beta activation in ICH. J Mol Neurosci 61: 385-395, 2017.

18. Pérez-Cabeza de Vaca R, Dominguez-López M, GuerreroCelis N, Rodriguez-Aguilera JR and Chagoya de Sánchez V: Inflammation is regulated by the adenosine derivative molecule, IFC-305, during reversion of cirrhosis in a $\mathrm{CCl}_{4}$ rat model. Int Immunopharmacol 54: 12-23, 2018.

19. Xu Y, Wang Y, Yan S, Yang Q, Zhou Y, Zeng X, Liu Z, An X, Toque HA, Dong Z, et al: Regulation of endothelial intracellular adenosine via adenosine kinase epigenetically modulates vascular inflammation. Nat Commun 8: 943, 2017.

20. Savio LEB, de Andrade Mello P, Figliuolo VR, de Avelar Almeida TF, Santana PT, Oliveira SDS, Silva CLM, Feldbrügge L, Csizmadia E, Minshall RD, et al: CD39 limits P2X7 receptor inflammatory signaling and attenuates sepsis-induced liver injury. J Hepatol 67: 716-726, 2017.

21. Livak KJ and Schmittgen TD: Analysis of relative gene expression data using real-time quantitative PCR and the 2(-Delta Delta C(T)) method. Methods 25: 402-408, 2001.

22. Tabas I and Glass CK: Anti-inflammatory therapy in chronic disease: Challenges and opportunities. Science 339: 166-172, 2013.

23. Dinarello CA, Simon A and van der Meer JW: Treating inflammation by blocking interleukin-1 in a broad spectrum of diseases. Nat Rev Drug Discov 11: 633-652, 2012.

24. Mascanfroni ID, Yeste A, Vieira SM, Burns EJ, Patel B, Sloma I, Wu Y, Mayo L, Ben-Hamo R, Efroni S, et al: IL-27 acts on DCs to suppress the $\mathrm{T}$ cell response and autoimmunity by inducing expression of the immunoregulatory molecule CD39. Nat Immunol 14: 1054-1063, 2013.

25. Jo EK, Kim JK, Shin DM and Sasakawa C: Molecular mechanisms regulating NLRP3 inflammasome activation. Cell Mol Immunol 13: 148-159, 2016

26. Zhong Z, Sanchez-Lopez E and Karin M: Autophagy, NLRP3 inflammasome and auto-inflammatory/immune diseases. Clin Exp Rheumatol 34 (4 Suppl 98): S12-S16, 2016.

27. Mao K, Chen S, Chen M, Ma Y, Wang Y, Huang B, He Z, Zeng Y, $\mathrm{Hu} \mathrm{Y}$, Sun S, et al: Nitric oxide suppresses NLRP3 inflammasome activation and protects against LPS-induced septic shock. Cell Res 23: 201-212, 2013.

28. Heneka MT, Kummer MP, Stutz A, Delekate A, Schwartz S, Vieira-Saecker A, Griep A, Axt D, Remus A, Tzeng TC, et al: NLRP3 is activated in Alzheimer's disease and contributes to pathology in APP/PS1 mice. Nature 493: 674-678, 2013.

29. Stearnskurosawa DJ, Osuchowski MF, Valentine C, Kurosawa S and Remick DG: The pathogenesis of sepsis. Annu Rev Pathol 6: 19-48, 2011.

30. Csóka B, Németh ZH, Törő G, Koscsó B, Kókai E, Robson SC, Enjyoji K, Rolandelli RH, Erdélyi K, Pacher P and Haskó G: CD39 improves survival in microbial sepsis by attenuating systemic inflammation. FASEB J 29: 25-36, 2015.

31. Bhat M, Romagnuolo J, da Silveira E, Reinhold C, Valois E, Martel M, Barkun JS and Barkun AN: Randomised clinical trial: MRCP-first vs. ERCP-first approach in patients with suspected biliary obstruction due to bile duct stones. Aliment Pharmacol Ther 38: 1045-1053, 2013.

32. Li F, Xu M, Wang M, Wang L, Wang H, Zhang H, Chen Y, Gong J, Zhang JJ, Adcock IM, et al: Roles of mitochondrial ROS and NLRP3 inflammasome in multiple ozone-induced lung inflammation and emphysema. Respir Res 19: 230, 2018.

33. Yu X, Zhao Q, Zhang X, Zhang H, Liu Y, Wu X, Li M, Li X, Zhang J, Ruan X and Zhang H: Celastrol ameliorates inflammation through inhibition of NLRP3 inflammasome activation. Oncotarget 8: 67300-67314, 2017.

34. Knowles JR: Enzyme-catalyzed phosphoryl transfer reactions. Annu Rev Biochem 49: 877-919, 1980.

35. Morandini AC, Savio LE and Coutinho-Silva R: The role of $\mathrm{P} 2 \mathrm{X} 7$ receptor in infectious inflammatory diseases and the influence of ectonucleotidases. Biomed J 37: 169-177, 2014.

36. Robson SC, Sévigny J and Zimmermann H: The E-NTPDase family of ectonucleotidases: Structure function relationships and pathophysiological significance. Purinergic Signal 2: 409-430, 2006.

This work is licensed under a Creative Commons Attribution-NonCommercial-NoDerivatives 4.0 International (CC BY-NC-ND 4.0) License. 